\title{
Masculinidades e Diáspora: classe, racializações e feminização do Outro
}

\author{
Masculinities and Diaspora: class, racializations and \\ feminization of the Other
}

\author{
Sofia Aboim* \\ Pedro Vasconcelos**
}

\begin{abstract}
Resumo - A partir de uma análise qualitativa sintética sobre homens imigrantes em Portugal, procura-se destrinçar as maneiras como as identidades migrantes são construídas de forma gendrificada, com diferenças relativas à constituição de comunidades diaspóricas específicas (Brasileiros, Cabo-verdianos e Moçambicanos), com origem em diferentes histórias coloniais e pós-coloniais. Para os homens migrantes, a experiência da alteridade, ainda que permeada por emaranhamentos culturais, hibridismo e inclusão social, é marcada, na maioria dos casos, pela subalternidade. As maneiras de lidar com a discriminação levam à construção de identidades migrantes, segundo origens nacionais, de forma altamente gendrificada, nomeadamente em termos de masculinidades. Ao mesmo tempo que os homens migrantes aspiram ao poder de formas variadas (nomeadamente pela reinvenção de múltiplas formas de performatividade corporal e sexual masculina), tendem também a afastar-se da inclusão na ordem de género dominante em Portugal, sendo frequentemente cúmplices involuntários da sua própria fetichização enquanto Outro.

Palavras-Chave: Masculinidade; hegemonia; subordinação; alteridade, migrações.
\end{abstract}

\begin{abstract}
Drawing on a qualitative research project on immigrant men in Portugal, we aim at disentangling the ways in which migrant identities are constructed in a gendered manner, with differences pertaining to the constitution of specific diasporic communities (Brazilians, Cape Verdeans and Mozambicans), hailing from diverse colonial and post-colonial histories. For mmigrant men, the experience of otherness, even if permeated by cultural entanglements, hibridity and social inclusion, is marked, in most cases, by subalternity. The ways of dealing with discrimination lead to the construction of migrant identities, along national lines of origin, in a highly gendered form, namely
\end{abstract}

\footnotetext{
* Socióloga. Investigadora Auxiliar (Instituto de Ciências Sociais, Universidade de Lisboa). Correspondência: Av. Prof. Aníbal Bettencourt 9, Lisboa, Portugal - Instituto de Ciências Sociais da Universidade de Lisboa. CEP: 1600-189. Email:<sofia.aboim@ics.ulisboa.pt>.

** Sociólogo. Professor Auxiliar (Instituto Universitário de Lisboa - ISCTE-IUL). Centro de Investigação e Estudos de Sociologia (CIES-IUL). Correspondência: Av. das Forças Armadas, Lisboa, Portugal - Centro de Investigação e Estudos de Sociologia do Instituto Universitário de Lisboa - ISCTE. CEP: 1649-026. Email: <pedro.vasconcelos@iscte.pt>
} 
in terms of masculinities. At the same time that migrant men aspire to power in many-sided ways (namely by reinventing multiple forms of male bodily ans sexual performativity), they also tend to shut themselves to inclusion in the dominant Portuguese gender order, frequently being, unwittingly, complicit with their own fetichization as Other.

Key Words: Masculinity; hegemony; subordination; otherness; migrations.

\section{Homens nas Margens: subalternidade e hegemonia}

A expansão de processos transnacionais e globais (do capitalismo à cultura) abriu caminho a novas formas de construção das masculinidades nas sociedades contemporâneas. Os movimentos migratórios do sul global para o norte global produzem novos desafios para muitos homens, nas suas vidas individuais, e para as ordens de género, enquanto estruturas institucionais. De facto, os constantes fluxos de corpos, informação e imagéticas de masculinidade, rapidamente deslocáveis de um contexto social para outro, têm colocado estimulantes e difíceis reptos à investigação sobre os homens e as masculinidades (Hearn, 2015).

Estes desafios necessariamente nos levam a reconsiderar criticamente a noção de masculinidade hegemónica, bem como as dinâmicas de poder que sustêm hierarquias gendrificadas de uns sobre outros, tal como Hearn (2009) indicou com o seu conceito de transpatriarcados. Por estas razões, avançar numa reflexão fundamentada sobre como homens em posições subordinadas (re)constroem as suas identidades e práticas por referências às normas de poder masculino, sucesso, virilidade e racialidade branca (os princípios-chave sustentadores da masculinidade hegemónica), é de primordial importância.

Concentrando-nos em diferentes categorias de homens imigrantes no Portugal contemporâneo e a partir de uma análise temática sintética dos dados, procuramos contribuir para um conhecimento empírico do 'subordinado' face ao hegemónico, bem como explorar os modos através dos quais identidades etnicizadas são construídas de forma gendrificada por homens que vivem processos de deslocação. Adicionalmente, procuramos examinar as fronteiras complexas entre o subordinado e o dominante, tal como discutir o conceito de masculinidade hegemónica e os problemas que levanta. A nossa preocupação central, indo das margens para o centro, foi a de investigar os processos de construção das masculinidades não-hegemónicas nas margens do padrão dominante - o do homem profissionalmente bem-sucedido, poderoso e sobretudo europeu ("branco" não-racializado). 


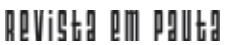

\} MASCULINIDADES E DIÁSPORA - ABOIM, S.; VASCONCELOS, P. \}

DOI: $10.12957 /$ REP.2016.27860

Na perspectiva que desenvolvemos, dando relevo às masculinidades migrantes, a diferenciação entre subordinação e dominação não é clara, já que não pode ser conceptualizada fora de uma visão que dê conta da complexidade do processo de produção da diferença e alteridade. Por outro lado, a ênfase na alteridade (Taylor, 1989) implica que perspectivemos a masculinidade como uma estrutura complexa de capitais mobilizados em permanentes lutas pela identidade como elemento de demonstração de uma forma de supremacia histórica e socialmente contextualizada (Hall, 1990). Estas lutas reinventam um poder do subordinado que, mesmo que problemático e guetizado, pode contribuir decisivamente para transformar o que a masculinidade hegemónica representa e, assim, levar-nos a questionar o que o próprio conceito significa, por oposição ao que não é hegemónico. Em suma, olhando para as margens torna-se talvez mais fácil desenredar as imagéticas e mesmo as contradições simbólicas do centro, ao mesmo tempo que, como propôs Homi Bahabha (1994) se reecontra a agência associada ou mesmo promovida pela condição, sempre situacional, da subalternidade.

A partir da década de 1980 iniciou-se um vasto debate sobre as masculinidades transnacionais (Connell e Messerschmidt, 2005), que levou a novas preocupações de investigação. Um importante tema tem sido o dos fluxos transnacionais de homens migrantes, em regra deslocando-se de países mais pobres do hemisfério sul para sociedades nacionais mais ricas do hemisfério norte, em busca de melhores condições económicas e de vida, frequentemente enfrentando dificuldades não antecipadas ou mesmo a desilusão face ao que projectavam. A pesquisa focada em homens migrantes tem vindo a desvendar as formas como masculinidades subordinadas e nas margens são frequentemente compelidas a mudar, pelo menos nalgum grau, quando os homens têm de se ajustar a diferentes ordens de género e a diferentes concepções e definições sociais de masculinidade hegemónica (Donaldson et al., 2009; Howson, 2009).

Uma masculinidade valorizada pode ser muitas coisas diferentes e levada a cabo de múltiplas maneiras. A miríade de símbolos associados à masculinidade e ao poder masculino permite aos homens a reconstrução da sua posição como sujeitos dominantes de formas igualmente múltiplas, pelo menos discursivamente. Mas o discurso também é poder, ainda que não devamos esquecer a base material de qualquer desigualdade. Homens imigrantes pobres não são poderosos, se definirmos poder em termos estritamente materialísticos, mas a sua subordinação global não os inibe de aspirar ao poder, seja ele material ou simbólico. Uma aspiração que tentam aliás demonstrar e realizar, particularmente em relação a mulheres, mas também em relação a outros homens, através de estratégias práticas e discursivas.

A reconstrução contemporânea das masculinidades gera uma talvez mais complexa hegemonia dos homens (Hodgson, 2001; Cornwall e 
Lindisfarne, 1994; Howson, 2009; Ong, 1999). Num mundo abalado por mudanças massivas nas relações de género, as vidas e identidades dos homens estão também em alteração, assim revelando, a um nível microsocial, a multiplicidade (Eisenstadt, 2000) e o emaranhamento das modernidades (Therborn, 2003).

Do ponto de vista do poder masculino no presente Portugal póscolonial e europeista, os homens imigrantes dão por si enredados entre diferentes 'mundos' de sentido. As relações de género não são imunes a mudanças globais, mas estão a desenvolver masculinidades híbridas e não apenas adaptativas aos modelos dominantes nas sociedades da Europa ocidental. Neste sentido, as masculinidades constituem um objecto e uma perspectiva de investigação que implicam múltiplos níveis de análise articulados entre si. É assim necessário o desenvolvimento de uma articulação entre abordagens materiais e discursivas do poder, evitando-se simultaneamente quer a reificação de uma qualquer masculinidade, quer a sua dissolução numa plétora infinda de discursos. Não obstante, ao afirmarmos que as masculinidades são múltiplas e que é reducionista falar de homens e de masculinidade como categorias uniformes, cairiamos igualmente em erro se esquecessemos que o poder dos homens é estrutural. O poder masculino dá assim forma a padrões societais consistentes, ao mesmo tempo que é também culturalmente moldável e individualmente incorporável de formas flexíveis (Connell e Messerschmidt, 2005; Hearn, 2004). Advogar tal estratégia conceptual e metodológica implica lidar com conceitos como patriarcado e masculinidade hegemónica sem, contudo, perder de vista a dominação e o poder como um conjunto de processos fluídos e até contraditórios, operando a múltiplos níveis e em última análise constitutivos dos próprios sujeitos (Foucault, 1977).

Neste sentido, uma discussão da definição de Connell das masculinidades como configurações múltiplas hierarquicamente organizadas é central. Contudo, se colocarmos os processos da dominação masculina no centro das relações de género temos ainda de encontrar instrumentos conceptuais que compreendam a dominação como estrutura, discurso e agencialidade. A este respeito, a noção marxista de 'apropriação' pode ser útil, caso se consiga ultrapassar uma definição materialista e se consiga expandir o conceito de apropriação à cultura e aos bens simbólicos, bem como à agência e à incorporação. O processo de incorporação (Bourdieu 1977) implica apropriação, e esta é sempre um processo de poder. Baseando-se no trabalho de Bhabha (1994) sobre apropriação e mimetismo, Demetriou (2001), entre outros, argumentou para que as masculinidades - particularmente a hegemónica - sejam concebidas como apropriando traços de masculinidades não-hegemónicas. A este respeito, as masculinidades são socialmente constituídas através de complexas lutas pela aquisição e realocação de certos símbolos e posições materiais. A incorporação e performatividade do género, ainda que ligadas a diferenciais de poder, im- 


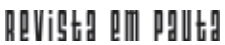

\} MASCULINIDADES E DIÁSPORA - ABOIM, S.; VASCONCELOS, P. \}

DOI: $10.12957 /$ REP.2016.27860

plicam processos de apropriação que devem necessariamente ser vistos como dinâmicos e fluídos. Em consequência, uma reflexão sobre o poder e a hegemonia deve sempre considerar o carácter híbrido da masculinidade.

Nas suas práticas, os homens usam permanentemente referências variadas, embora não propriamente através das mais pacíficas negociações. A masculinidade hegemónica não é apenas um símbolo de dominação sobre as mulheres e outras formas de masculinidade, mas é antes particularmente dependente de tensões internas. Uma dificuldade adicional emerge sempre que se procura traçar as principais características da hegemonia. Por outras palavras, o problema principal é porventura o de encontrar uma forma heurística de distinguir entre o que é hegemónico e o que não é e em que contexto tal assim é.

\section{Homens migrantes numa sociedade pós-colonial}

Este artigo desenvolve-se a partir de uma análise das masculinidades diaspóricas de homens imigrantes que vivem na capital portuguesa, Lisboa, concentrando-se particularmente em homens brasileiros. Este trabalho fez parte de um projecto de investigação mais vasto sobre homens não-dominantes e as suas estratégias para lidar com a subalternidade e a dominação. A selecção de homens imigrantes, num total de 45 entrevistas em profundidade, procurou alcançar uma vasta diversidade de histórias coloniais e pós-coloniais face ao centro colonizador.

A maioria dos entrevistados (20) foram brasileiros, hoje o mais importante grupo migrante na sociedade portuguesa. As relações do Brasil com a antiga potência colonial são ambíguas, ainda que o Brasil possa ser caracterizado como uma sociedade de povoamento colonial (com importantíssimos contributos africanos e indígenas, quer demograficamente, quer culturalmente). Por um lado, a independência brasileira foi alcançada bastante cedo, em 1822, tendo a sociedade brasileira sido desde sempre recipiente de migrantes portugueses. Estes, e por contágio também Portugal, particularmente a partir da abolição da escravatura em 1888, foram crescentemente vistos de forma estereotipada e depreciativa. É claro que esta depreciação dos portugueses ocorreu no âmbito das complexas classificações e dinâmicas raciais e de classe da sociedade brasileira. Apesar de retóricas persistentes de democracia racial, o Brasil apresenta ainda um sistema hierárquico de categoriais raciais e de cor cujo cume permanece branco e europeu em detrimento do negro, africano, pardo, moreno, índio, etc. Por outro lado, nas últimas décadas e apesar de flutuações consoante os ciclos económicos, Portugal começou a ser crescentemente percebido no Brasil como um país rico da Europa ocidental, cuja cultura é muitas vezes percepcionada por brasileiros como semelhante à sua - não só linguisticamente, mas também noutras dimensões, como a sociabilidade. 


\section{Revigta p p p. pattg}

\} MASCULINIDADES E DIÁSPORA - ABOIM, S.; VASCONCELOS, P. \}

DOI: $10.12957 /$ REP.2016.27860

Os nossos entrevistados brasileiros apresentavam uma diversidade de características sociais, correspondendo na maioria esmagadora dos casos a processos de migração economicamente motivada. As suas origens geográficas eram múltiplas - cinco eram originários de Minas Gerais, três de Espírito Santo e os restantes distribuíam-se pelo Mato Grosso do Sul, Bahia, Brasília, Pernambuco, Paraíba, Rio de Janeiro, São Paulo, Paraná e Santa Catarina. A maioria encontrava-se em Portugal a trabalhar assalariadamente, embora um deles usufruísse de uma bolsa de doutoramento portuguesa. As inserções profissionais variavam também, mas a maioria pode caracterizarse como trabalho pouco qualificado nos serviços ou indústria (desde empregados de restauração, vendedores de loja, auxiliares de cozinha, até pedreiros e serventes da construção civil, etc.) - isto de forma relativamente independente do seu grau de escolaridade. No entanto, alguns detinham inserções mais qualificadas (três no total), como quadros licenciados ou mesmo administradores de empresas, além do já referido estudante-bolsista de doutoramento numa universidade portuguesa. Apenas oito dos entrevistados tinham frequentado ou concluído um grau superior de ensino. Do ponto de vista das auto-categorizações raciais, sete dos entrevistados descreviamse como brancos, sendo que os restantes usavam uma plêiade de categorias raciais brasileiras - moreno, pardo, cafuzo, etc.

Os outros dois grupos entrevistados, moçambicanos (15 entrevistas) e cabo-verdianos (10 entrevistas), representam antecedentes coloniais muito diferentes - os do colonialismo português tardio em África - e exemplificam estratégias opostas de colonização.

Moçambique apenas alcançou a independência em 1975, depois de 13 anos de guerra de libertação nacional contra o regime ditatorial e conservador de direita do Estado Novo (1926-1974)1 e somente apenas depois da revolução de esquerda em 1974, que estabeleceu a democracia parlamentar em Portugal. A declaração de independência seria seguida pela guerra civil moçambicana entre 1976 e 1992 (no contexto da Guerra Fria), que, entre outros impactos, incapacitou fortemente os esforços de desenvolvimento da sociedade moçambicana. Durante o séc. XX o colonialismo português em Moçambique foi altamente racialista: não só a distinção legal entre 'negros' e 'brancos' era primordial (utilizando para tal múltiplos sistemas categoriais), como as populações africanas eram sistematicamente compelidas ao trabalho forçado. A partir de 1961, com o começo da guerra colonial, o povoamento europeu aumentou significativamente. O sistema colonial então preponderante era basicamente similar ao apartheid, algo potenciado (quando comparando com Angola, por exemplo) pela proximidade da África do Sul e pela importância de interesses econó-

\footnotetext{
${ }^{1}$ De facto, em sentido estrito, o Estado Novo vai de 1933 (data da Constituição Política da República Portuguesa de 1933) até 1974 (data da Revolução de 25 de Abril de 1974), sendo o período de 1926 (data da Revolução de 28 de Maio de 1926) até 1933 chamado de Ditadura Nacional ou Ditadura Militar.
} 


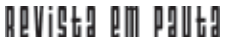

\} MASCULINIDADES E DIÁSPORA - ABOIM, S.; VASCONCELOS, P. \}

DOI: $10.12957 /$ REP.2016.27860

micos britânicos em Moçambique. Logo a partir da independência verificaram-se fluxos migratórios em direcção a Portugal, que se acentuaram a partir de 1980.

A independência de Cabo Verde foi igualmente apenas alcançada em 1975, ainda que o seu território insular nunca tenha sido palco de actuações militares durante a guerra colonial portuguesa (1961-1974). A sociedade cabo-verdiana, no entanto, resultou de uma história colonial bastante diferente das restantes colónias portuguesas em África (com a excepção relativa do arquipélago de São Tomé e Príncipe). As ilhas de Cabo Verde não eram habitadas antes da descoberta portuguesa em 1460. A estratégia colonial seguida pelas autoridades portuguesas produziu aí uma sociedade mista, resultante do cruzamento entre colonizadores portugueses e populações negras continentais africanas deslocadas, ainda que o poder tenha sempre permanecido em posse de uma elite branca (essencialmente masculina) enviada a partir de Lisboa para administrar e controlar o território e a população local. Esta hibridez social e cultural - patente na língula crioula cabo-verdiana - faz de Cabo Verde uma sociedade e cultura mais próxima do mundo crioulo das Antilhas do que de África continental. Globalmente os cabo-verdianos não tendem a categorizar-se como 'negros' ou 'pretos', mas como 'mestiços' ou 'mulatos'. Apesar destas diferenças, também a imigração cabo-verdiana para Portugal acentuou-se com a declaração de independência e o início da década de 1980.

Estes dois grupos de entrevistados, tal como os brasileiros, apresentavam diversidade das suas características sociodemográficas. Em ambos os casos, moçambicanos e cabo-verdianos, parte estava em Portugal para continuação dos estudos universitários, tendo origem em famílias das fracções de classe mais escolarizadas das suas sociedades nacionais, e parte correspondia a processos migratórios de cariz económico, com perfis de baixa escolaridade e inserções sócio-profissionais com pouca exigência qualificacional e baixa remuneração, particularmente no sector da construção civil.

Portugal, a antiga potência colonial e sociedade receptora destes fluxos migratórios, como país semiperiférico em relação aos centros do capitalismo mundial, caracterizou-se até 1974 como uma sociedade altamente deficitária em termos de desenvolvimento socioeconómico e ela própria com elevados níveis de emigração. Tal dinâmica global só começaria a ser invertida com o fim da ditadura autoritária, conservadora e colonialista. No contexto desta, ainda que as práticas coloniais portuguesas fossem fortemente racistas, o discurso oficial era um de denegação, antes elogiando a suposta inexistência de discriminação racial e o colonialismo brando e integrativo de Portugal. O discurso ocultava e legitimava assim a violência das práticas coloniais (informais e formais). A sociedade portuguesa contemporânea é permeada por categorizações raciais, resultado histórico de uma longa tradição colonial, bem como de séculos de discriminação anti- 
judaica e anti-mourisca. No presente, dadas as características igualitárias da Revolução dos Cravos de 25 de Abril de 1974, a sociedade e cultura portuguesas caracterizam-se por modalidades sistemáticas de 'racismo subtil' (da cognição à acção), ainda que o discurso oficial e o enquadramento legal (a começar pela Constituição da República) sejam activa e explicitamente anti-racistas (o que não quer dizer que não existam processos de racismo institucional, ainda que ocultos e indirectos). Paralelamente, e no respeitante ao género, até meados dos anos setenta, os discursos oficiais e legais em Portugal propalavam e reforçavam uma ordem de dominação masculina fortemente patriarcal. Tal mudou radicalmente. Não só a democracia portuguesa formalizou a absoluta igualdade entre homens e mulheres, interditou constitucionalmente e criminalizou a discriminação de género, bem como desenvolveu políticas de igualdade de género anti-conservadoras, como também, acompanhando uma notória queda do força institucional e cultural do catolicismo, profundas mudanças sociais, desde a elevada taxa feminina de actividade laboral paga, até à disseminação de estilos de vida fortemente individualizados ou aos direitos LGBT, produziram uma ordem de género mais simétrica.

Ao investigarmos estes grupos de homens imigrantes - brasileiros, moçambicanos e cabo-verdianos - preocupavam-nos algumas questões analíticas. Nomeadamente, como aplicar categoriais conceptuais como hegemónico e subordinado à análise de homens ou masculinidades não-hegemónicas ou discriminadas? E como combinar perspectivas materiais e discursivas do poder sem negligenciar a agencialidade dos subordinados? Como táctica analítica, focamo-nos nas aspirações destes homens imigrantes em ser/tornar-se/ter os capitais ausentes da masculinidade, analisando as diferentes estratégias e discursos de auto-empoderamento quando lidam com a alteridade - aquele que é outorgado pelo próprio estatudo de imigrante independentemente de outros eixos interseccionais de subalternização -, escrutinando a rebelião e o protesto como forma de escaparem à sujeição, mas olhando igualmente para modalidades de masculinidade contraditórias e cúmplices e identidades comunitárias.

\section{Masculinidades diaspóricas e a dialéctica da alteridade}

Numa apresentação geral e sintética dos resultados obtidos, estes demonstram que estes três grupos de homens imigrantes apresentam formas algo diferentes de lidar com o deslocamento, embora algumas comunalidades também existam.

Parte significativa dos entrevistados declara ter sido objecto de discriminação e desvalorização/subalternização. Evidentemente não se trata aqui de ensaiar qualquer tipologia extrapolável além dos limites das amostras de homens que retraram uma diversidade de pertenças e posiciona- 


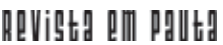

\} MASCULINIDADES E DIÁSPORA - ABOIM, S.; VASCONCELOS, P. \}

DOI: $10.12957 /$ REP.2016.27860

mentos. Trata-se, antes, de mostrar como os processos de alterização estão presentes, quaiquer que sejam os seus conteúdos específicos, na construção de si face a um outro, ou no caso, da construção da masculinidade entre hegemonia e subordinação.

Voltando aos entrevistados, alguns desses relatos de discriminação são explícitos e vincados. Como nos disse um estudante de licenciatura cabo-verdiano de 23 anos: "Aqui em Portugal há muito racismo". O mesmo entrevistado apontou aliás outra dimensão típica dos processos discriminatórios, a estereotipização categorial: "Para os portugueses, os caboverdianos são todos bandidos!" Um dos entrevistados brasileiros (46 anos, empregado de supermercado, ensino secundário completo) igualmente fez eco dessa estereotipização sobre os brasileiros - "Tão sempre dizendo que brasileiro é tudo igual!" - acrescentando o quanto sofreu por causa da discriminação: "Que essa vida tão... sofrida, aqui em Portugal. Isso aqui foi o que eu chamo de inferno..." No mesmo sentido, outro entrevistado brasileiro (28 anos, pedreiro, ensino secundário completo) afirmava sobre os portugueses "Eles acham que brasileiro...entendeu, é tudo de favela, é tudo ladrão, é tudo prostituta... eles tem muito preconceito, entendeu?"

De facto, estas modalidades estereotipizantes parecem ser um dos elementos centrais dos processos discriminatórios sofridos pelos nossos entrevistados em interacções variadas. Elemento contra o qual alguns dos homens que entrevistamos sentem ter que estar sempre a contrariar. Como afirmou um dos homens brasileiros (27 anos, vendedor numa loja, licenciado):

Acho que há uma coisa de você ser visto como inferior... até as pessoas que gostam de mim e dizem 'ah é brasileiro mas é gente boa' sabe? Esse 'mas', é como tipo se tivesse que provar que você é uma pessoa honesta, provar que é uma pessoa legal, provar que é uma pessoa trabalhadora, provar que não é um promíscuo... você tem sempre que provar que é um bom brasileiro... sabe? Não é que todo o brasileiro seja filha da puta, mas tem que provar...há sempre uma desconfiança... quando você fala que é brasileiro, sempre tem um... é atrás... é que você é visto como subcategoria...que era uma experiência que nunca tinha passado antes...é visto como um pária assim...

Isto produz em muitos claros sentimentos de desvalorização, como afirmou outro entrevistado brasileiro (35 anos, servente da construção civil, ensino secundário incompleto), a propósito da mesma questão: "V̧ocê não 'tá no seu país... então isso tira um pouco a auto-estima do homem!"

E claro que nem todos os entrevistados dão conta desta experiência. Alguns, particularmente no caso de parte dos moçambicanos e cabo-verdianos, menorizam bastante qualquer situação de discriminação que possam eventualmente ter vivido, dizendo sempre, laconicamente, que não passaram por isso, ou então que não deixam que isso aconteça. Por parte de alguns destes, esta recusa corresponderá não apenas a uma realidade 


\section{hevigtg aाm pguttg}

\} MASCULINIDADES E DIÁSPORA - ABOIM, S.; VASCONCELOS, P. \}

DOI: $10.12957 /$ REP.2016.27860

de fraca discriminação explícita, mas também a uma incorporação e minimização cognitiva da discriminação que antecipavam. Como nos disse um dos entrevistados moçambicanos (31 anos, servente da construção civil desempregado, ensino secundário incompleto): "Eu já vinha preparado p'ra isso, por isso..." Os homens brasileiros entrevistados, de uma forma geral, são mais lestos em afirmar que foram vítimas de discriminação, provavelmente também porque não a antecipavam, até porque, inversamente, os passados coloniais recentes dos entrevistados africanos os predispõem à incorporação (por mais que contraditória e dissonante) de uma desvalorização recente por parte de portugueses.

É claro que a discriminação sofrida não remete apenas para circunstâncias de interacção onde tratamentos desvalorizadores são activados. Remete igualmente para situações objectivas e materiais de exploração. Quando mais frágil e precária do ponto de vista laboral é a situação dos entrevistados, mais explicitações de discriminação ocorrida se verificam. Daí que nos casos de inserção socioprofissional mais qualificado, não só por causa dessa mesma inserção (de menor precariedade, maior remuneração e estatuto simbólico), mas também porque os contextos de interacção laborais tendem a ser mais formais e vigiados pelas normatividades da 'boa-educação', a discriminação possa não se dar (material, mas também na interacção, pelo menos explicitamente).

Tal está bem patente no caso, particularmente, dos entrevistados brasileiros com melhores posições profissionais, onde o elevado nível educacional e remuneratório, bem como uma aparência racial apercebida como branca (para mais se fortalecida com invocação de ascendência recente exclusivamente europeia), acompanhada de performatividades linguísticas, corporais e estilísticas de classe mais alta, produzem não só a uma não-declaração ou mesmo recusa de experiências discriminatórias, mas até a discursos, não sem contradições - é certo, de valorização de Portugal e dos portugueses, em detrimento do Brasil.

É assim claro que as circunstâncias de discriminação são propiciadas (ou, inversamente, menorizadas) pela intersecção de múltiplos factores. Não só se verificam processos de estereotipização étnico-nacional diversificados (poderíamos mesmo dizer, de etnicização), como a posição de classe (e associados capitais escolares e económicos), a aparência 'racial', a língua falada (sotaque, nível de formalidade e correcção gramatical e vocabular, etc.), a hexis corporal e vestuário, entre outros factores, são dimensões centrais destes processos.

Por outro lado, a assumpção de se ter sido objecto de discriminação está também associada, mesmo que em contradição com os anteriores processos, ao nível de expectativa de valorização anteriormente incorporado. Quanto maior a expectativa de valorização (logo, de não discriminação), maior será tendencialmente o ressentimento face ao mínimo indício discriminatório. 


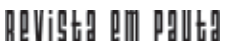

\} MASCULINIDADES E DIÁSPORA - ABOIM, S.; VASCONCELOS, P. \}

DOI: $10.12957 /$ REP.2016.27860

No entanto, quer tenham sentido e declarado, ou não, terem sido alvo de processos de subalternização e desvalorização (simbólica e material), todos os entrevistados estão envolvidos no que podemos apelidar de dialéctica da alteridade.

De forma resumida, eles são o Outro. Embora uns mais que outros, consoante a matriz de proximidades e distâncias das suas características em relação aos portugueses (ou, pelo menos, das suas características como apercebidas pelos portugueses em relação às características que estes projectam sobre si próprios). Ao mesmo tempo, a sua alteridade fetichizada (Ahmed 2000) é um processo complexo através do qual alguns destes homens imigrantes também transformam os homens portugueses e europeus (tal como as mulheres) em 'outros', como estratégia de valorização de si e da pertença e origem nacional. A alteridade é sedimentada como forma de reconhecimento mútuo, o que permite aos subordinados ganhos identitários, já que desenvolvem várias estratégias de desapossamento do dominante.

Ainda que encontremos práticas mimetizadoras dos dominantes (dos portugueses, mas acima de tudo de algumas das imagéticas da masculinidade europeias ou norte-americanas), todos os nossos entrevistados expressaram necessidades de auto-empoderamento pela recriação da diferença. Uma diferença construída essencialmente através do corpo e da sexualidade como espécie de arma da verdadeira masculinidade. Masculinidade essa que, enquanto virilidade corpóreo-sexual, denegam aos portugueses e europeus em geral. ${ }^{2}$ Estes são apresentados de forma geralmente emasculada e a sua constante feminização (como homens fracos dominados por mulheres indesejáveis) mostra claramente como o feminino é ainda e persistentemente uma forte estratégia de desvalorização. Para os nossos entrevistados moçambicanos os homens portugueses são "homens numa garrafa", para os cabo-verdianos são fracos, para os brasileiros são sexualmente impotentes e incapazes de conquistarem mulheres.

As declarações neste sentido são múltiplas e recorrentes e verbalizadas pela maioria dos entrevistados. Como afirmou um dos homens caboverdianos (27 anos, técnico de informática, formação pós-secundária não superior): "Eu acho que os portugueses são muito chorões, digamos assim..." Ou então um entrevistado brasileiro (25 anos, empregado de mesa, ensino secundário): "Em muitas vezes eu ouço dizer que são muito frouxos, não conseguem..." Os exemplos podiam ser multiplicados. Claro que as declarações tendem a ser tanto mais explicitadas quanto maiores os sentimentos de discriminação sofrida. E esta é tanto maior quanto maior a distância face ao centro normativo das características valorizadas dos e pelos portugueses (sejam elas reais ou fantasmáticas), isto é, quanto maior o posicionamento marginal dos entrevistados em relação a esse centro. Ou seja,

\footnotetext{
${ }^{2}$ Resultados semelhantes foram verificados em relação à percepção de homens turcos ou de origem turca residentes na Alemanha sobre os homens alemães (ver Bohnsack, Loos, \& Przyborski, 2001).
} 


\section{hevigtg aाm pguttg}

\} MASCULINIDADES E DIÁSPORA - ABOIM, S.; VASCONCELOS, P. \}

DOI: $10.12957 /$ REP.2016.27860

quanto menor o poder social (económico, escolar, etc.), quanto maior a alteridade racial em relação ao sujeito definido como branco e quanto maior a distância cultural (linguística, hexis, rituais de interacção, sociabilidade, etc.) em relação a Portugal, maior será a subalternidade e desapossamento dos homens imigrantes. E quanto maior esta subalternidade e marginalização, maiores serão tendencialmente as estratégias de desvalorização do dominante, sobressaindo, dentro dessas estratégias simbólicas, a feminização.

No mesmo sentido, ainda como comunalidade, os homens portugueses, vistos como fracos ou efeminados (senão mesmo gays), seriam os parceiros dominados de mulheres masculinizadas que nunca conseguem verdadeiramente satisfazer (sexualmente). Mulheres frequentemente apresentadas pelos nossos entrevistados como sexualmente não-atraentes, frustradas, que se comportam como homens e que não sabem ser verdadeiramente femininas, tem demasiada pilosidade corporal e não se sabem arranjar ou seduzir. São múltiplas e quase repetitivas, com parcas excepções, as declarações de elogio às mulheres brasileiras, pelos brasileiros, ou às africanas, pelos moçambicanos e cabo-verdianos. Não só as mulheres portuguesas são apresentadas com um valor sexual e erótico parco ou negativo ("As mulheres brasileiras são mais atrevidas, são mais sensuais e as mulheres portuguesas na maioria não são sensuais..." - homem brasileiro, 28 anos, empregado de loja, ensino secundário), como são masculinizadas. Esta masculinização das mulheres portuguesas não constitui, no entanto, uma sua valorização, mas antes e acima de tudo uma desvalorização dos homens portugueses. Como afirmou um dos entrevistados brasileiros (29 anos, auxiliar de cozinha, ensino superior): "As portuguesas... elas querem mandar num homem, elas gritam com eles e eles baixam a cabeça!"

São igualmente comuns nos nossos entrevistados as generalizações depreciativas sobre a "cultura portuguesa", com isto referenciando as lógicas da interacção e da sociabilidade. Não só tendem a dar-se elogios da sensualidade e informalidade brasileiras e africanas (ou até mesmo da capacidade de festa e divertimento), como se dá relevo e ênfase à sinceridade das relações - por suposta oposição ao carácter frio, dessexualizado e instrumental ou utilitarista dos portugueses. Como nos disse um dos entrevistados caboverdianos (27 anos, estudante de mestrado) sobre os relacionamentos no seu país de origem:

É uma relação muito mais amistosa, menos instrumentada, menos material, menos consumista e mais orientada para a amizade sincera, da cordialidade, da sinceridade e de valores que são trazidos da sociedade africana. Esses valores, aqui nas sociedades europeias ocidentais, não são valores assim tão salientes.

Esta ideia do carácter mais genuíno dos relacionamentos é também frequentemente associada a ideias de maior capacidade de festa e até 


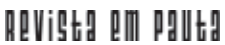

\} MASCULINIDADES E DIÁSPORA - ABOIM, S.; VASCONCELOS, P. \}

DOI: $10.12957 /$ REP.2016.27860

mesmo de sensualidade e erotismo (como supostos indicadores dessa maior genuinidade). Segundo as palavras de um dos entrevistados brasileiros (35 anos, engenheiro civil em empresa privada, mestrado): "Eu acho que isso vem da nossa cultura brasileira, de ser uma cultura muito mais sexual do que a cultura portuguesa."

É claro que todas estas estratégias de desvalorização são sempre estratégias de desvalorização do dominante, com tudo o que isso tem de dissonância cognitiva - está-sempre face a um processo que, almejando a auto-valorização, tem sempre de lidar, incessante e ressentidamente, com a subalternidade imposta.

Apesar destes traços em comum, não obstante as variações, as dificuldades sentidas pelos nossos entrevistados em lidarem com modalidades de discriminação especificamente racializada produzem diferentes respostas, claramente sustentadas pelas suas respectivas histórias coloniais e por visões ambivalentes de Portugal como nação europeia e colonizadora.

Por outras palavras, as formas como lidam com a supremacia da racialidade 'branca' - característica no mínimo implícita da auto-imagem da maioria dos portugueses - são marcadamente diferentes devido a processos históricos de colonialismo também diferentes, bem como a dinâmicas pós-coloniais de racialização também elas divergentes.

Para a maioria dos nossos entrevistados brasileiros, ${ }^{3}$ face à surpresa de serem objecto, em Portugal, de categorização racial potencialmente não-branca (já que muitos se descrevem como sendo "brancos no Brasil", ou pelo menos como "não-negros"), as estratégias variam entre uma espécie de assumpção orgulhosa da 'mistura brasileira', ou uma recusa em aceitar a classificação discriminatória de não-branco mas sem contestação dos critérios classificatórios (procurando antes a afirmação discursiva da conformidade ao aspecto racial de homem branco, ou pelo menos uma aproximação a isso, com diluição de uma alteridade racial mais distante).

A recusa das categorizações raciais portuguesas está bem patente no discurso de um dos entrevistados brasileiros (28 anos, empregado de loja, ensino secundário):

Às vezes eu fico um bocado enervado, porque eu não estou habituado a ser chamado de mulato ou até preto. Como no Brasil nós temos muita diversidade, eu sou considerado moreno. ${ }^{4}$ Um mulato é mais escuro do que eu ainda, é quase um preto e até mesmo o cabelo... As pessoas às vezes compararam-me, tu és mulato, és assim, ou és

\footnotetext{
${ }^{3}$ É claro que quando os entrevistados brasileiros apresentavam traços fenotípicos que, face aos critérios classificatórios portugueses, os faziam ser caracterizados sem ambiguidade como brancos (ou seja, de suposta origem completamente europeia), tal surpresa e categorização subordinante não se dava, apesar de uma persistente suspeição sobre a ancestralidade dos brasileiros (suspeição essa também relatada pelos nossos entrevistados).

${ }^{4}$ De notar que, em termos das categorizações raciais operantes em Portugal, moreno nunca é um descritor linguístico (já que não chega a atingir qualidades categoriais claras) que seja aplicado a alguém considerado não-branco (a não ser de forma explicitamente irónica). Moreno designa, no geral e apenas, alguém "branco" que tem cabelo e olhos escuros e/ou um tom de pele "bronzeado".
} 
assado, tens o cabelo frisado, mas às vezes eu me sinto um bocado ofendido em ouvir isto, porque eu não sou uma pessoa racial comigo mesmo.

Esta recusa é sempre não somente uma recusa de definições identitárias estrangeiras ao ideário categorial e de auto-definição de partida (que é sempre também um ideário de posicionamento face a outrem), mas igualmente uma recusa de processos de desvalorização e discriminação sentida na chegada. O mesmo entrevistado continua:

Mesmo não sendo negro negro negro, mas tenho uma pele moreno escura, e por 'tar num país onde noventa por cento é da pele branca então você sente-se que você é... mesmo que a pessoa tente disfarçar, mas você vê que a pessoa tem uma certa discriminação por você...

No mesmo sentido, outro entrevistado brasileiro (29 anos, bolseiro de doutoramento) também reafirma a realidade da discriminação e elogia o hibridismo brasileiro:

Tenho mais pigmentação que muita gente, principalmente aqui em Portugal (riso)! Onde você é uma pessoa de cor, onde você tem traços ... e onde você vive numa sociedade praticamente toda caucasiana... e as pessoas meio que discriminam isso onde o padrão do homem perfeito seria branco... Eu sou um híbrido de várias raças, de várias etnias, de várias coisas. Eu me sinto privilegiado por ser um híbrido disso!

Outro ainda (26 anos, empregado de mesa, mestrado) relata a suspeição de não-brancura que cai sobre os brasileiros e a tentativa de a reafirmar: "E aí ele disse, 'Tu achas que és branco, não?!' (mimetizando o sotaque e gramaticalidade portuguesa). E aí eu... Ehh eu sou um branco, mas não... Mas de coração preto!"

Estas respostas por vezes sobrepõe-se e confundem-se, com laivos frequentes de dissonância cognitiva ou mesmo contradição, tendencialmente sempre em discursividades marcadamente nacionalistas e de desvalorização de Portugal e dos portugueses - como vimos através de esquemas de feminização, mas também através de desvalorizações raciais em comparação quer com a superioridade da "mistura" quer com as populações da Europa mais a norte, supostamente "mais brancas".

Por seu lado, os homens cabo-verdianos entrevistados, muitos dos quais recusam descrever-se como negros ou pretos ("Preto é na Guiné!", disse-nos um dos entrevistados, 26 anos, servente de construção, ensino secundário incompleto), chegando mesmo a dizer que os cabo-verdianos são os "brancos de África" e tendendo a salientar frequentemente traços físicos estereotipicamente não-africanos (olhos ou cabelos claros, por exemplo), demonstram forte ambiguidade em lidar com a descoberta, em 


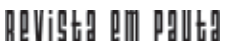

\} MASCULINIDADES E DIÁSPORA - ABOIM, S.; VASCONCELOS, P. \}

DOI: $10.12957 /$ REP.2016.27860

Portugal, da sua negritude (e negritude como desvalor). Como afirma um dos entrevistados (29 anos, estudante de licenciatura): "Eu penso que a questão da cor da pele é o marcador mais importante que acaba por orientar as tendências discriminatórias. Mas eu... Eu não tenho raça! Ou então, estou no meio, sou mestiço."

Por um lado, é patente como a sua identidade nacional é, à partida, racializada (por distinção/aproximação em relação a África continental e aproximação/distinção à antiga metrópole colonizadora). Por outro lado, a força da discriminação racial e da sua inclusão tendencial em Portugal numa categoria genérica de negro (ou, menos eufemisticamente, preto, ou, mais eufemisticamente, africano), faz crescer sentimentos de distância em relação a Portugal e aos portugueses e de acentuação da sua africanidade. Um dos entrevistados (31 anos, servente de construção, ensino secundário incompleto) afirmou:

Não é preciso dizer preto, ou assim, para notares que as pessoas sentem algum receio. Eu vi pessoas fugirem de mim. Sou preto, sou alto, sou grande! Mas foi difícil ver que as pessoas me olhavam negativamente pela cor da minha pele. Sou preto sim! E depois?!

Estes sentimentos e respostas permanecem emaranhados, mas sempre face a um contexto global de desvalorização enquanto Outro subalterno, que os faz frequentemente reverter a estratégias (nomeadamente gendrificadas) de desvalorização do Outro dominante. Isto ao mesmo tempo que o lugar do dominante é cobiçado. Outro entrevistado cabo-verdiano (33 anos, empregado bancário, licenciatura incompleta) disse-nos:

Há aquele estigma, se calhar... um africano tem um QI mais baixo, não é? Se estás nas limpezas, nas ruas, nos restaurantes... ninguém te chateia, estás no teu habitat natural. Mas quando começas a galgar terrenos e a ter trabalhos qualificados, já começas a incomodar muita gente! Têm é medo, parecem umas meninas!

Os homens moçambicanos que entrevistámos, ainda que, previamente e sem ambiguidades, conscientes da sua negritude, sentem mesmo assim a reiteração para lá das suas expectativas dessa negritude como condição ontologicamente desvalorizadora. De facto, muitos chegaram a dizernos que só perceberam em Portugal que eram vistos primeiro como negros e depois como homens ou mesmo pessoas. Aquilo que era uma categorização acessória da sua subjectividade torna-se num critério primeiro, essencialista e objectivamente imposto do seu (des)valor social. Como afirmou um dos entrevistados (36 anos, operador de posto de abastecimento, ensino secundário incompleto): "Raça... não gosto nada disso. Eu sou negro, mas isso não é importante. Ou não devia ser!" Por outro lado, alguns dos homens reforçam os seus sentimentos identitários (moçambicano, 45 anos, 


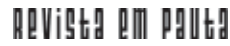

\} MASCULINIDADES E DIÁSPORA - ABOIM, S.; VASCONCELOS, P. \}

DOI: $10.12957 /$ REP.2016.27860

cozinheiro, ensino secundário incompleto): "É uma bênção (ser negro)... Fogo! Eu não queria ser branco! Agora o branco não foi escravizado..."

De certo modo, as velhas ideias do luso-tropicalismo, pelas quais os portugueses seriam mais suaves, menos racistas e mais abertos a performatividades corporais estereotipicamente tropicalistas, quebram-se definitivamente para estes homens. E é necessário acrescentar que estas populações, além dos processos especificamente indicados acima, sofrem de todas as circunstâncias habituais de exclusão, marginalização e exploração que tende a caracterizar as populações imigrantes em sociedades do norte global (exploração laboral, nomeadamente). ${ }^{5}$

Os portugueses emergem assim aos seus olhos, como distantes, frios e brancos (ou inequivocamente europeus, ainda que por vezes europeus de $2^{\underline{a}}$ categoria, por comparação com os países mais ricos do norte da Europa). Correlativamente, os nossos entrevistados descobrem-se mais Outro do que poderiam imaginar, caindo numa dialéctica da alteridade e recorrem ao jogo da diferença para reconquistarem poder e valor. A subordinação que vivem (nacional, migrante, racial, etc.) tem de ser contrariada, e tende a sê-lo através não da inversão ou anulação de critérios de subordinação, mas, paradoxalmente, pela sua mobilização contra os dominantes, nomeadamente utilizando a subordinação do feminino para desvalorizar homens dominantes (os portugueses, os europeus).

É claro que não nos deparamos com uma única resposta por parte destes homens migrantes para contrariar a subalternidade. A própria noção de uma dialéctica da alteridade é tal que compreende desde logo a noção associada de uma multiplicidade de estratégias, que não têm necessidade de irem todas no mesmo sentido, podendo ser cruzada, inverter o rumo, contradizer-se.

\section{A comodificação da masculinidade em contextos pós-coloniais}

A análise sintética dos dados empíricos induz a uma reflexão sobre o que alguns autores denominaram de comodificação da masculinidade, sendo de prestar especial atenção aos modos como os discursos dos homens apontam para lutas entre a dominação e a sujeição. É de notar que, ao falarmos de comodificação, estamos a reproduzir as maneiras como os homens organizam os seus discursos e práticas, sendo atribuído um certo valor a um certo bem (material ou simbólico). Tal mimetiza, de certa maneira, as dinâmicas capitalistas da troca económica. Uma variedade de símbolos é apropriada pelos homens e usada performativamente para levar a cabo a masculinidade e evitar sentimentos de exclusão. Podemos dizer,

\footnotetext{
${ }^{5}$ Note-se que os nossos entrevistados são, na sua maioria, imigrantes com profissões de baixo rendimento, fraco reconhecimento e instabilidade contractual, e não expatriados (que é uma forma eufemística de dizer imigrantes de 'luxo' com elevadas inserções sócioprofissionais e elevado capital simbólico).
} 


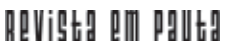

\} MASCULINIDADES E DIÁSPORA - ABOIM, S.; VASCONCELOS, P. \}

DOI: $10.12957 /$ REP.2016.27860

seguindo Baudrillard (1996) sobre o 'sistema dos objectos', que signos e símbolos podem ser trocados como mercadorias na medida em que o sentido (que pode ser considerado equivalente ao conceito de valor em definição marxiana) é criado pela diferença.

Os homens empoderam-se de maneiras múltiplas e usam um vasto número de imagéticas e discursividades da masculinidade, das mais tradicionais às mais modernistas. Pelo uso do corpo e acentuação das dimensões sexuais e de potência/conquista como se fossem 'capitais' da masculinidade, os homens trocam reflexivamente as suas capacidades corporais (da violência/força à sexualidade) numa espécie de mercado de bens onde o corpo e a sexualidade são vistos como opostos (e supostamente mais verdadeiros) a outros recursos possíveis, como o dinheiro e formas de poder institucional ou hierárquico. Estas estratégias permitem que homens marginalizados alcancem uma percepção de que podem ser valorizados como homens, na ausência relativa de recursos económicos ou outras formas de poder material.

Resulta daqui que os homens portugueses são emasculados pela percepção desvalorizante de que são menos viris e mais fracos/moles. Tornam-se assim 'outros' num complexo e algo incoerente jogo performativo e discursivo de alteridade.

Estes processos podem ser reconstruídos pelas categorias que os homens usam para se descreverem e para descreverem outros. Contudo, tais rótulos representam o entrelaçamento de diferentes categorias simbólicas - as dos países de origem dos nossos entrevistados, as dos discursos coloniais, as do Portugal contemporâneo. Tal emaranhamento aumenta, aliás, com a inclusão de imagéticas globais. O que é relevante é que a maioria destes rótulos representam uma espécie de rebelião contra o poder exercido por outros, mas, simultaneamente, relevam também uma vontade activa de não ser excluído daquilo que é hegemónico na masculinidade. Assim, estas formas alternativas ou mesmo mercantilizadas de construção da masculinidade são somente rebeliões parciais (ou mesmo superficiais), na medida em que não contribuem para a emancipação das mulheres e do feminino e sujeitam-se ao patriarcado, pelo menos na maioria dos casos.

Mais importante do que apresentar uma listagem de imagéticas locais e globais, o que poderia resultar somente na descrição (tendencialmente reificadora) de um certo número (limitado) de tipos de masculinidade, é compreender o processo que subjaz ao uso de categorias discursivas deste tipo, em contribuem em última análise para a manutenção da hegemonia dos homens (Hearn 2004).

Nesta linha de raciocínio, existem três processos-chave que devem necessariamente ser tomados em conta na análise das masculinidades diaspóricas em contexto global e transnacional: aspiração, mimetização e desencantamento. Os homens, tais como os nossos entrevistados, aspiram à emancipação e à sua quota-parte da hegemonia (Howson 2009) - o que 


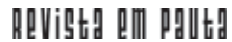

\} MASCULINIDADES E DIÁSPORA - ABOIM, S.; VASCONCELOS, P. \}

DOI: $10.12957 /$ REP.2016.27860

amiúde vêm como inalcançável. Na tentativa de escapar à subordinação, enquanto imigrantes discriminados e explorados, a mimetização joga um papel central, na medida em que são constituídas profundas conjugações entre diferentes símbolos geradoras de novas categorias bem como de novas formas de levar a cabo a masculinidade. Existe também, contudo, um certo grau de desencantamento, produto da frustração e sentimentos de inatingibilidade. Tal é patente quando analisamos as maneiras como os homens entrevistados manipulam as categorias da alteridade. E tal é também flagrante quando tomamos em consideração os sentimentos verbalizados de exclusão e mesmo maus-tratos que afectam número significativo de homens imigrantes. Estes vêm-se, assim, privados dos 'bens' materiais e simbólicos que lhes outorgariam uma masculinidade poderosa. De certa maneira, o desencantamento está profundamente associado à consciência da alienação e privação de reconhecimento e redistribuição (Honneth e Fraser 2003).

Finalmente, uma conclusão central está relacionada com a importância do capitalismo transnacional na reprodução do poder e da desigualdade. Mais do que apenas um modo material de produção, o capitalismo - e as discursividades mercantilizadas e utilitaristas que sustenta aprece quase como uma realidade 'ontológica' que, de forma marcada, implica unir o simbólico e discursivo com as bases materiais que sustentam ainda uma ordem de género patriarcal, ou, por outras palavras, a continuidade do patriarcado.

A concepção da masculinidade como capital só pode ser entendida desta maneira. Maneira que, é claro, é altamente devedora à teorização de Marx sobre o valor e os muitos desenvolvimentos que daí se deram. Neste sentido, a noção de capital inclui e entrelaça sempre dimensões discursivas e materiais. As semânticas comodificadas das masculinidades nas margens estão, neste sentido, fortemente ligadas à hegemonia dos homens, que implica diferentes mas eficientes estratégias de apropriação, através de formas sofisticadas de competição, do valor socialmente produzido, seja material ou simbólico. 


\section{Referências}

AHMED, S. Strange Encounters: Embodied Others in Post-Coloniality. London: Routledge, 2000.

BAUDRILLARD, J. The system of objects. London: Verso, 1996 [1968].

BHABHA, H. Location of Culture. London: Routledge, 1994.

BOHNSACK, R.; LOOS, P.; PRZYBORSKI, A. "Male honor": Towards an understanding of the construction of gender relations among youths of Turkish origin. In Baron, B.; Kotthoff, H. (eds.). Gender in Interaction: Perspectives on Femininity and Masculinity in Ethnography and Discourse. 175207. Amsterdam \& Philadelphia: John Benjamins Publishing Company, 2001.

BOURDIEU, P. Outline of a Theory of Practice. Cambridge: Cambridge University Press, 1977.

CONNELL, R.W.; MESSERSCHMIDT, J.W. Hegemonic masculinity: Rethinking the concept. Gender and Society, 19(6): 829-59, 2005.

CORNWALL, A.; LINDISFARNE, N. (eds.). Dislocating Masculine - Comparative Ethnographies. New York: Routledge, 1994.

DONALDSON, M.; HIBBINS, R.; HOWSON, R.; PEASE, B. (eds.). Migrant Men: Critical Studies of Masculinities and the Migration Experience. New York: Routledge, 2009.

DEMETRIOU, D. D. Connell's concept of hegemonic masculinity: a critique. Theory and Society, 30: 337-61, 2001.

EISENSTADT, S. N. Multiple modernities. Daedalus, 129(1): 1-29, 2000.

FOUCAULT, M. Discipline and Punish: The Birth of the Prison. New York: Vintage, 1977.

HALL, S. Cultural Identity and Diaspora. In: Rutherford J. (ed.). Identity: Community, Culture, Differences. London: Lawrence and Wishart, 1990.

HEARN, J. From hegemonic masculinity to the hegemony of men. Feminist Theory, 5(1), 97-120, 2004.

HEARN, J. Patriarchies, transpatriarchies and intersectionalities. In: Oleksy, E. (ed.). Intimate Citizenships: Gender, Sexualities, Politics. 177-192. London: Routledge, 2009.

HEARN, J. Men of the World: Genders, Globalizations, Transnational Times. Londres: Sage, 2015.

HODGSON, D. L. Gendered Modernities: Ethnographic perspectives, London: Palgrave Macmillan, 2001. 


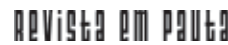

\} MASCULINIDADES E DIÁSPORA - ABOIM, S.; VASCONCELOS, P. \}

DOI: $10.12957 /$ REP.2016.27860

HONNETH, A.; FRASER, N. Redistribution or Recognition?: A PoliticalPhilosophical Exchange, London: Verso, 2003.

HOWSON, R. Deconstructing hegemonic masculinity. Nordic Journal for Masculinity Studies, 4: 7-21, 2009.

ONG, A. Flexible Citizenship: The Cultural Logics of Transnationality. Durham: Duke University Press, 1999.

TAYLOR, C. Sources of the Self: The Making of the Modern Identity. Cambridge: Harvard University Press, 1989.

THERBORN, G. Entangled Modernities. European Journal of Social Theory, 6(3): 293-305, 2003.

Recebido em 08 de fevereiro de 2017.

Aprovado para publicação em 15 de fevereiro de 2017. DOI: 10.12957/rep.2016.27860

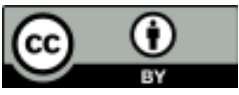

A Revista Em Pauta: Teoria Social e Realidade Contemporânea está licenciada com uma Licença Creative Commons Atribuição 4.0 Internacional. 